\title{
Transparent bionanocomposites with improved properties prepared from acetylated bacterial cellulose and poly(lactic acid) through a simple approach
}

\author{
Liliana C. Tomé, Ricardo J. B. Pinto, Eliane Trovatti, Carmen S. R. Freire,* Armando J. D. Silvestre, \\ Carlos Pascoal Neto and Alessandro Gandini
}

Received 13th September 2010, Accepted 29th November 2010

DOI: $10.1039 / \mathrm{cogc00545b}$

\begin{abstract}
The preparation and characterization of biocomposite materials with improved properties based on poly(lactic acid) (PLA) and bacterial cellulose, and, for comparative purposes, vegetal cellulose fibers, both in their pristine form or after acetylation, is reported. The composite materials were obtained through the simple and green mechanical compounding of a PLA matrix and bacterial cellulose nanofibrils (or vegetable fibers), and were characterized by TGA, DSC, tensile assays, DMA, SEM and water uptake. The bionanocomposites obtained from PLA and acetylated bacterial cellulose were particularly interesting, given the considerable improvement in thermal and mechanical properties, as evidenced by the significant increase in both elastic and Young moduli, and in the tensile strength (increments of about 100, 40 and 25\%, respectively) at very low nanofiller loadings (up to $6 \%$ ). These nanocomposites also showed low hygroscopicity and considerable transparency, features reported here for the first time.
\end{abstract}

\section{Introduction}

The recent emphasis on sustainable and environmentally friendly materials and processes is steering the trends of composite technology away from traditional materials like nondegradable thermoplastic matrices, such as polyolefins and polyurethanes reinforced with conventional fillers (i.e. glass, aramid or carbon fibers, for instance). The present tendency is to use fully biodegradable biocomposites ("green" composites) obtained by blending natural fibers with biodegradable polymers. A high diversity of natural fibers (e.g. jute, ramie, sisal, pulp fibers and several nanocellulosic substrates like cellulose whiskers, microfibrilated cellulose (MFC) and bacterial cellulose (BC), among others) and a considerable number of biodegradable matrices (polysaccharide derivatives, proteins and polyesters, among others) are progressively available for use in such green composites. $^{1}$

Poly(lactic acid) (PLA) is a versatile biodegradable thermoplastic polyester entirely produced from renewable resources, specifically starch enriched products like sugar beet, corn and wheat. ${ }^{2}$ This thermoplastic biopolymer has properties (high mechanical strength and stiffness, UV stability and gloss, among others) that are comparable to those of many commodity

CICECO and Department of Chemistry, University of Aveiro, 3810-193, Aveiro, Portugal.E-mail: cfreire@ua.pt; Fax: +351 234370 084;

Tel: +351234370604 polymers like polystyrene and polypropylene, and has, thus, gained increasing attention and interest in several fields of application, such as the automotive industry, packaging and medicine.

Over the past few years, a considerable number of studies dealing with the reinforcement of PLA with several natural fibers, ${ }^{3-7}$ microcrystalline cellulose, ${ }^{8}$ as well as with nanoscale cellulose substrates, namely MFC, ${ }^{9-11}$ cellulose whiskers, ${ }^{12-15}$ and bacterial cellulose, ${ }^{16-17}$ have been reported in the literature. However, certain limitations have frequently been pointed out, such as the occurrence of fiber aggregation and poor fiber-polymer matrix interfacial compatibility, which are intrinsic consequences of the high hydrophilic and polar character of cellulose substrates. Fiber aggregation is particularly troublesome with nanoscale cellulose fillers like MFC and BC due to their high aspect ratio and surface area. Several strategies have been suggested to overcome these problems, such as the use of compatibilizers (i.e. chitosan, ${ }^{18}$ cellulose esters, ${ }^{19}$ maleated polypropylene ${ }^{20}$ ), coupling agents ${ }^{21-22}$ and chemical modification of the cellulose fibers (i.e. by reactive compatibilization ${ }^{23}$ and esterification with organic acids $\left.{ }^{24-25}\right)$.

Lee et $a l .{ }^{24}$ recently reported the cellulose surface esterification with organic acids (acetic, hexanoic and dodecanoic acids) as a strategy to produce PLA/BC nanocomposites with improved properties. However, in general, the obtained materials displayed similar, or even lower, mechanical and thermal properties compared to the use of unmodified BC nanofibers. Additionally, 
Tingaut et al. ${ }^{25}$ reported the preparation of PLA composites with acetylated MFC. These PLA/acetylated MFC composites demonstrated improved filler dispersion and water resistance but, in most cases, their dynamic-mechanical properties were again similar to those measured with unmodified MFC. Moreover, the reported materials were not transparent and were obtained using an environmentally harmful approach based on a chloroform solution casting method.

Despite the drawbacks mentioned above, considering the chemical structure of PLA, the acetylation of cellulose substrates under appropriate conditions should be one of the most straightforward and viable ways to improve PLA matrix-cellulose fiber compatibility. Following this idea and our interest in the development of new cellulose based materials, ${ }^{26-30}$ we describe in the present work the preparation and characterization of composite materials based on PLA and vegetal or bacterial cellulose (both pristine and after acetylation), obtained through a simple and green mechanical compounding of the different components. Among these, the nanocomposite materials based on PLA and acetylated bacterial cellulose showed a particularly interesting enhanced thermal stability and mechanical properties, together with a low water uptake and high transparency.

\section{Experimental}

\section{Materials}

Poly(lactic acid) (PLA) in the form of pellets, with an L: D ratio of $98: 4$ and an $M_{\mathrm{w}}$ of $110000 \mathrm{~g} \mathrm{~mol}^{-1}$ (from Cargill-Dow Polymers) was gently ceded by Prof. John Dorgan. Bacterial cellulose (BC) (three-dimensional network of nano- and microfibrils of 10-200 nm width) in a shredded wet form ( $95 \%$ humidity) was supplied by Forschungszentrum für Medizintechnik und Biotechnologie e.V. (Germany). The vegetable cellulose fibers (VC) used in this study were in the form of an industrial Eucalyptus globulus ECF (DEDED) bleached kraft pulp, kindly provided by a Portuguese pulp mill, composed essentially of cellulose $(\sim 85 \%)$ and glucuronoxylan $(\sim 15 \%)$, and minor amounts of lipophilic extractives $(\sim 0.4 \%))^{31}$

\section{Cellulose substrates acetylation}

Before modification, the $\mathrm{BC}$ was disintegrated with Ultra-Turrax equipment for $30 \mathrm{~min}$ at $20500 \mathrm{rpm}$, and then solvent exchanged with ethanol and acetone, with three dispersion/filtration sequences for each solvent. The acetylation methodology used in this work was adapted from an established procedure: ${ }^{32}$ $225 \mathrm{~mL}$ of acetic anhydride was placed in a $500 \mathrm{~mL}$ roundbottomed flask followed by $0.9 \mathrm{wt} \%$ of $\mathrm{H}_{2} \mathrm{SO}_{4}(0.75 \mathrm{~mL})$, and finally $\mathrm{BC}$ or $\mathrm{VC}(15 \mathrm{~g})$ was added under stirring. The treatment was then conducted at $30^{\circ} \mathrm{C}$ for $4 \mathrm{~h}$. At the end of the reaction, the esterified $\mathrm{BC}$ and $\mathrm{VC}$ fibers were filtered and sequentially washed with acetone, ethanol, water and again with ethanol. Then, to remove any residual trace of acetic anhydride and other impurities, the modified fibers were Soxhlet extracted with ethanol for $12 \mathrm{~h}$ and finally dried at $60{ }^{\circ} \mathrm{C}$ for $24 \mathrm{~h}$.
Table 1 Identification of the PLA/BC and PLA/VC composites prepared in this study

\begin{tabular}{llll}
\hline Sample & Cellulose substrate & Modification & $\mathrm{wt} \%$ of fibers \\
\hline PLA & - & - & - \\
& & & 1 \\
PLA-BC1 & Bacterial cellulose & - & 4 \\
PLA-BC4 & & - & 6 \\
PLA-BC6 & & - & 1 \\
PLA-BCAc1 & & $\mathrm{Ac}_{2} \mathrm{O}$ & 4 \\
PLA-BCAc4 & & $\mathrm{Ac}_{2} \mathrm{O}$ & 6 \\
PLA-BCAc6 & & & \\
& & - & 10 \\
PLA-VC10 & Vegetable cellulose & - & 20 \\
PLA-VC20 & & - & 30 \\
PLA-VC30 & & $\mathrm{Ac}_{2} \mathrm{O}$ & 10 \\
PLA-VCAc10 & & $\mathrm{Ac}_{2} \mathrm{O}$ & 20 \\
PLA-VCAc20 & & $\mathrm{Ac}_{2} \mathrm{O}$ & 30 \\
PLA-VCAc30 & & & \\
\hline
\end{tabular}

\section{Compounding and processing}

Composites were prepared by compounding PLA with the unmodified and acetylated $\mathrm{VC}$ and $\mathrm{BC}$ fibers in a melting mixer (Haake Rheomix 600P) working at $190^{\circ} \mathrm{C}$. The PLA pellets were charged and melted before adding the fibers. The systems were mixed for $10 \mathrm{~min}$ at $100 \mathrm{rpm}$. Different BC and VC loads were tested (Table 1). Subsequently, the composites were molded in a Thermo-Haake Minijet II injection molding machine for tensile (bar according to ISO 527-2-5A) and DMA analysis.

\section{Characterization of fibers and composites}

The materials were characterized using FTIR spectroscopy, elemental analysis, X-ray diffraction (XRD), contact angle measurements, UV-vis spectroscopy, thermogravimetry (TGA), differential scanning calorimetry (DSC), dynamical mechanical analysis (DMA), tensile tests, scanning electron microscopy (SEM) and water absorption tests.

FTIR spectra were acquired using a Brücker IFS 55 FTIR spectrometer equipped with a single horizontal Golden Gate ATR cell: the resolution was $8 \mathrm{~cm}^{-1}$ after 128 scans. Spectra were collected from 4000 to $500 \mathrm{~cm}^{-1}$.

The degree of substitution (DS) of the esterified BC membranes was determined by elemental analyses, as described elsewhere, ${ }^{33}$ using a Leco CNHS 932 elemental analyzer. Each sample was analyzed in triplicate.

XRD patterns were measured using a Phillips X'pert MPD diffractometer using $\mathrm{Cu}-\mathrm{K} \alpha$ radiation.

Contact angles $(\theta)$ with water, formamide, ethylene glycol and diiodomethane were measured $5 \mathrm{~s}$ after deposition of the droplet (to ensure the attainment of equilibrium) using a Surface Energy Evaluation System commercialized by Brno University (Czech Republic). Each reported value is the average of five determinations. Surface energies (including the polar and dispersive components) of the fibers before and after acetylation were calculated by applying the Owens-Wendt approach. ${ }^{34}$

Optical spectra were recorded using a Jasco V-560 UV-vis spectrophotometer. Spectra were recorded in diffuse reflectance mode using $\mathrm{MgO}$ as the reference at room temperature in steps of $1 \mathrm{~nm}$ in the range $400-700 \mathrm{~nm}$. 
SEM micrographs of the composite fractured surfaces were obtained using an SU-70 instrument. Samples were coated with evaporated carbon.

TGA assays were carried out using a Shimadzu TGA 50 analyzer equipped with a platinum cell. Samples were heated at a constant rate of $10{ }^{\circ} \mathrm{C} \mathrm{m^{-1 }}$ from room temperature to $800{ }^{\circ} \mathrm{C}$ under a nitrogen flow of $20 \mathrm{~mL} \mathrm{~min}^{-1}$. The thermal decomposition temperature was taken as the onset of significant $(\geq 0.5 \%)$ weight loss, after the initial moisture loss.

DSC thermograms were obtained in a Shimadzu DSC-50 apparatus calibrated with indium. Samples $(5-10 \mathrm{mg})$ were analyzed by heating-cooling cycles between 25 and $120^{\circ} \mathrm{C}$ under nitrogen at a scan rate of $10{ }^{\circ} \mathrm{C} \min ^{-1}$ using $40 \mu \mathrm{L}$ aluminium standard pans.

DMA measurements were carried out with a Tritec 2000 DMA Triton equipment in bending (single cantilever) mode. Tests were performed at $1 \mathrm{~Hz}$ and the temperature was varied from -10 to $130{ }^{\circ} \mathrm{C}$ in $4{ }^{\circ} \mathrm{C}$ steps.

Mechanical analyses were performed at room temperature using a Sintech | 6 tester equipped with an MTS 647 Hydraulic Wedge Grip using a load cell of $4.45 \mathrm{kN}$ and a deformation rate of $5.00 \mathrm{~mm} \mathrm{~min}^{-1}$.

\section{Water uptake}

Composite specimens (dimensions $60 \times 10 \times 1 \mathrm{~mm}$ ) were immersed in distilled water at room temperature to study their water uptake. A minimum of three samples were tested for each material. The weight increase was periodically assessed for 1 month. Samples were taken out of the water, their wet surfaces immediately wiped dry, weighed and then re-immersed. The water uptake at time $t, W_{\text {uptake }}$, was calculated as:

$$
W_{\text {uptake }}=\left(\frac{W_{\mathrm{t}}-W_{0}}{W_{0}}\right) \times 100
$$

where $W_{0}$ is the specimen's initial weight and $W_{\mathrm{t}}$ is the specimen's weight after immersion time $t$.

\section{Results and discussion}

\section{Acetylation of the cellulose substrates}

The heterogeneous acetylation of both bacterial (BC) and vegetable (VC) cellulose fibers was performed according to the literature, ${ }^{32}$ using reaction conditions (temperature and reaction time) that limited the modification at the fibers' surface, in order to preserve their mechanical properties. The success of the modification was clearly confirmed by FTIR spectroscopy, mainly based on the emergence of a new band at around $1735 \mathrm{~cm}^{-1}$, normally assigned to the carbonyl ester group stretching mode (Fig. 1). ${ }^{35}$ The DS (degree of substitution) attained was 0.02 and 0.06 , respectively, for $\mathrm{BC}$ and $\mathrm{VC}$ acetylated fibers.

The effect of surface acetylation on the fibers' crystallinity was assessed by XRD (Fig. 2). As is well known, both unmodified $\mathrm{BC}$ and VC fibers display the typical XRD pattern of cellulose $\mathrm{I}^{36}$ with the main diffraction signals at around $2 \theta 14.9,16.3$, 22.5 and $34.6^{\circ}$ normally attributed to the diffraction planes 101 , $10 \overline{1}, 002$ and 040, respectively. The acetylated BC and VC fibers

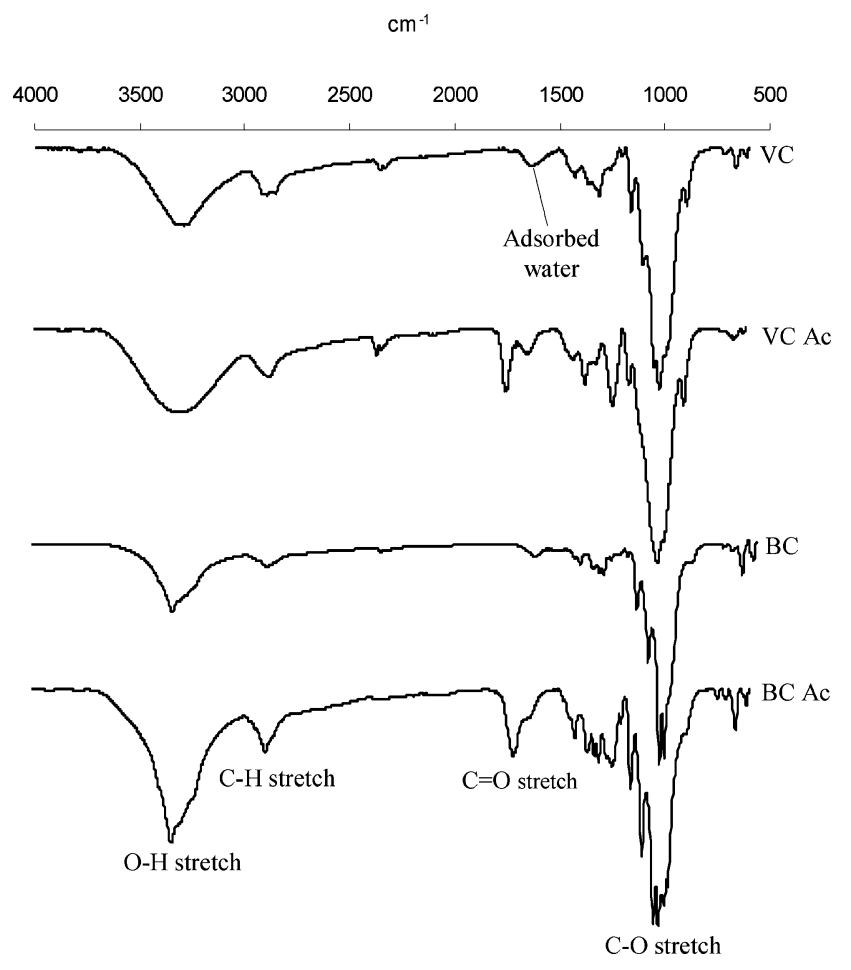

Fig. 1 FTIR spectra of BC and VC before and after acetylation.

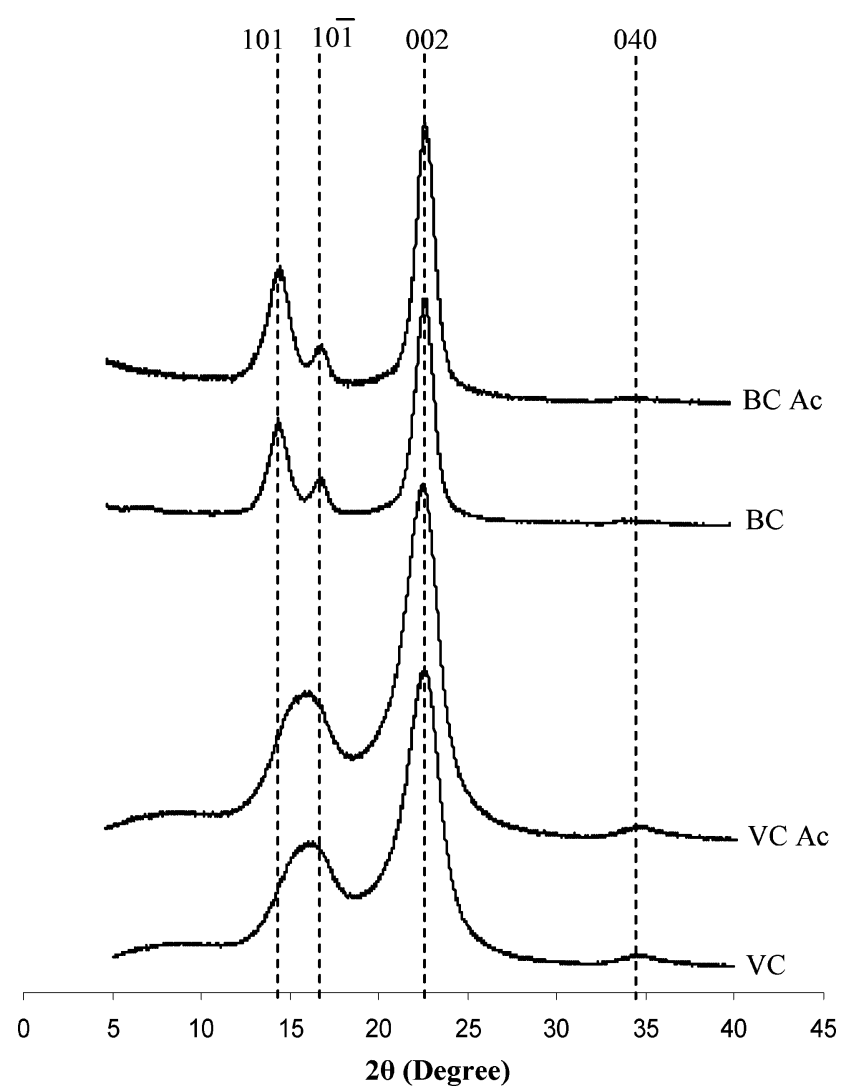

Fig. 2 X-Ray diffractograms of $\mathrm{BC}$ and $\mathrm{VC}$ before and after acetylation.

also presented this diffraction pattern, which indicates that the modification was essentially limited to the fibers' surface or to 
Table 2 Thermal data for the BC and VC samples, before and after acetylation, as obtained from the TGA plots

\begin{tabular}{lll}
\hline Sample & $T_{\left.\mathrm{di}\left(5^{\circ}\right)\right)} /{ }^{\circ} \mathrm{C}$ & $T_{\mathrm{d} \max } /{ }^{\circ} \mathrm{C}$ \\
\hline BC & 293 & $349(53)$ \\
BCAc & 257 & $329(61)$ \\
VC & 285 & $364(55)^{a}$ \\
VCAc & 271 & $343(53)$
\end{tabular}

${ }^{a}$ Numbers in parentheses refer to the percentage of decomposition attained at $T_{\mathrm{d} \max }$.

the more accessible amorphous cellulose domains, not affecting to any detectable extent the crystalline regions of the inner layers in the cellulose fiber, and therefore the main mechanical and morphological properties of the unmodified fibers.

The impact of acetylation on the thermal stability and degradation profile of $\mathrm{BC}$ and $\mathrm{VC}$ was evaluated by thermogravimetry. In general, the acetylated $\mathrm{BC}$ and $\mathrm{VC}$ fibers showed TGA profiles similar to those of pristine substrates, which showed a typical single weight loss feature, with a maximum decomposition temperature in the range $350-365^{\circ} \mathrm{C}$ (Table 2). However, the acetylated fibers were less stable, since they started to decompose at lower temperatures, particularly in the case of acetylated BC fibers. This slight decrease in thermal stability is commonly found in surface-acetylated cellulose fibers. ${ }^{26-27}$

In the present context, the main objective of the acetylation was the decrease in the fibers' hydrophilicity and polarity, aimed at increasing their adhesion to the PLA matrix. The surface energy of the BC and VC fibers before and after acetylation (Table 3) showed a considerable enhancement of the hydrophobic nature of the surface of the acetylated BC and VC fibers with a corresponding increase in the contact angle with polar liquids (water, formamide and ethylene glycol). The decrease in the surface energy of both cellulose substrates after acetylation was essentially due to the reduction in its polar component (Table 3) because of the replacement of some of the surface hydroxyl groups with acetyl moieties.

\section{Acetylated BC/PLA and VC/PLA composite characterization}

PLA biocomposites were prepared using unmodified and acetylated $\mathrm{BC}$ and $\mathrm{VC}$, with fiber contents from 1 to $6 \%$ for the $\mathrm{BC}$ composites and from 10 to $30 \%$ for the VC counterparts (Table 1). The different BC and VC contents tested were limited
Table 3 Contact angles $\left(\theta /{ }^{\circ}\right)$ on $\mathrm{BC}$ and $\mathrm{VC}$ with different liquids before and after acetylation and the corresponding $\operatorname{polar}\left(\gamma_{\mathrm{s}}^{\mathrm{p}}\right)$, dispersive $\left(\gamma_{\mathrm{s}}^{\mathrm{d}}\right)$ and total $\left(\gamma_{\mathrm{s}}\right)$ surface energy components

\begin{tabular}{|c|c|c|c|c|}
\hline & \multicolumn{4}{|c|}{ Sample } \\
\hline & $\mathrm{BC}$ & BCAc & $\mathrm{VC}$ & VCAc \\
\hline \multicolumn{5}{|c|}{ Contact angle $\left(\theta /{ }^{\circ}\right)$} \\
\hline Water & $42.8 \pm 0.7$ & $63.9 \pm 0.7$ & $56.3 \pm 0.4$ & $80.1 \pm 0.9$ \\
\hline Formamide & $42.6 \pm 0.8$ & $52.1 \pm 0.9$ & $41.0 \pm 1.2$ & $56.6 \pm 0.7$ \\
\hline Ethylene glycol & $46.5 \pm 1.7$ & $63.7 \pm 1.4$ & $54.5 \pm 1.7$ & $73.5 \pm 0.4$ \\
\hline Diiodomethane & $32.1 \pm 0.9$ & $43.0 \pm 0.7$ & $33.1 \pm 0.8$ & $42.4 \pm 0.5$ \\
\hline \multicolumn{5}{|c|}{ Surface energy $\left(\mathrm{mJ} \mathrm{m}^{-2}\right)$} \\
\hline$\gamma_{\mathrm{s}}{ }^{\mathrm{p}}$ & 20.29 & 10.59 & 12.87 & 3.44 \\
\hline$\gamma_{\mathrm{s}}{ }^{\mathrm{d}}$ & 30.26 & 28.74 & 32.97 & 31.99 \\
\hline$\gamma_{\mathrm{s}}$ & 50.56 & 39.32 & 45.84 & 35.43 \\
\hline
\end{tabular}

by the nature of the cellulose substrates (nano character of BC) and the experimental conditions used for the preparation of the composites, namely the high viscosity of the melted polymeric PLA matrix. The materials were, in general, quite homogenous, except for those with unmodified BC and VC cellulose fibers, which showed to the naked eye some fiber agglomeration. Moreover, the nanocomposites with acetylated BC were also still quite transparent compared with the unfilled PLA (Fig. 3). The transmittance (measured for specimens with a thickness of approximately $1 \mathrm{~mm}$ ) at around $580 \mathrm{~nm}$ was about $80 \%$ for PLA, 70\% for PLA-BCAc1, and $60 \%$ for the PLA-BCAc4 and PLA-BCAc6 nanocomposites. All the composites were then characterized in terms of morphology, thermal and mechanical properties, and water uptake capacity.

\section{Morphology}

A selection of SEM micrographs of the fractured surface of nanocomposite materials with $6 \%$ of $\mathrm{BC}$ and acetylated $\mathrm{BC}$, and of composites with $10 \%$ of VC fibers is shown in Fig. 4. For each material, two different magnifications were used in order to display both the $\mathrm{BC}$ and $\mathrm{VC}$ dispersion within the PLA matrix, and the interfacial adhesion between the two composite components.

The SEM micrographs of the composites with unmodified BC nanofibers (Fig. 4A) clearly show that the interfacial adhesion between the PLA matrix and the BC nanofibers is quite poor, because the nanofibers are, in part, pulled out from the matrix
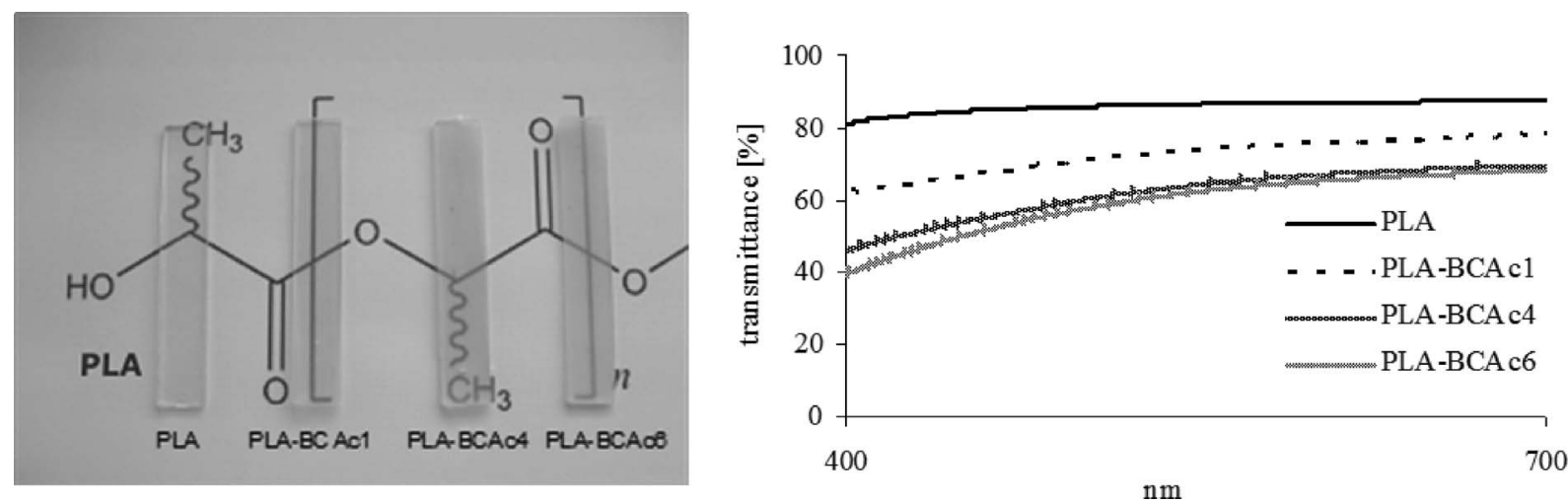

Fig. 3 Images of PLA/BCAc nanocomposite films and corresponding transmittance in the visible region. 
A
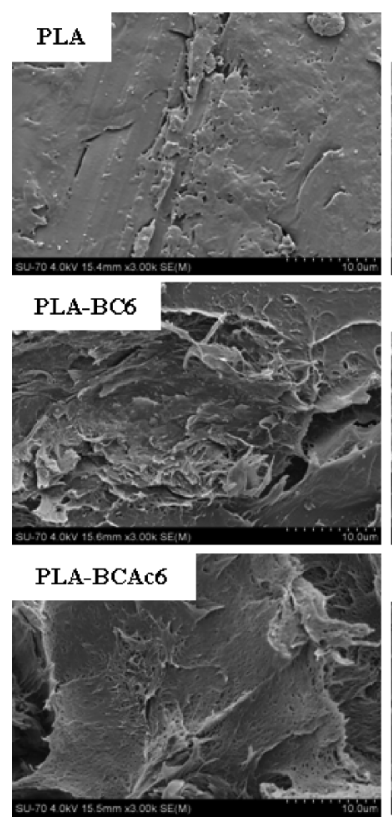
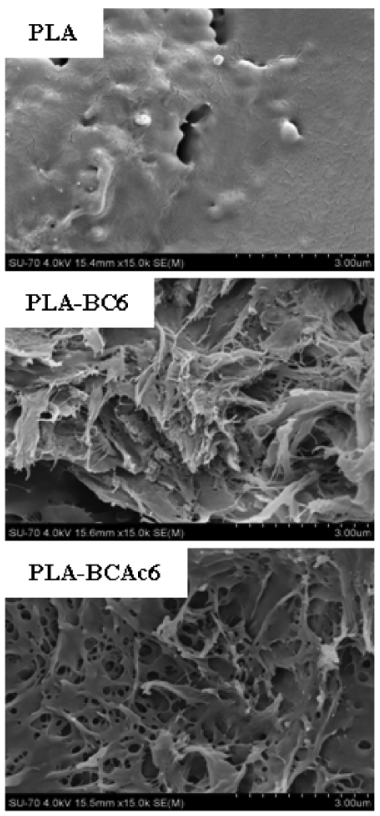

B
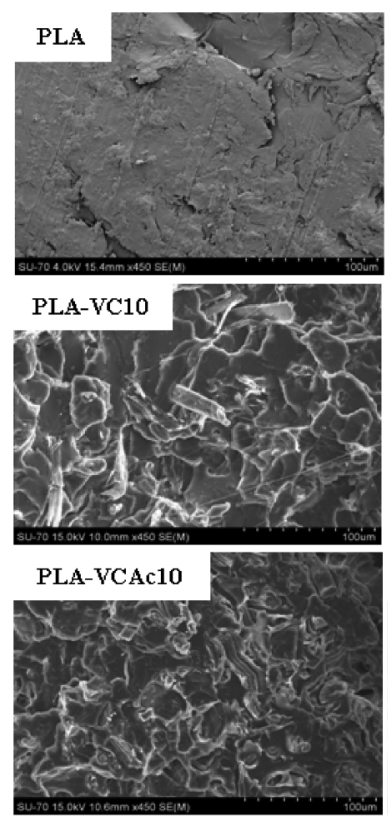

PLA
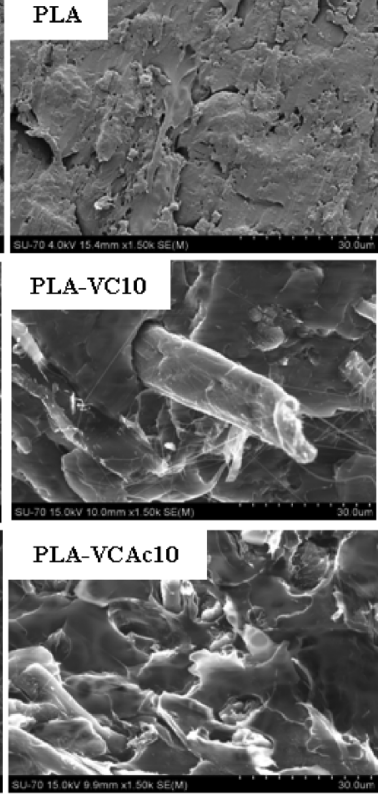

Fig. 4 SEM micrographs of PLA and selected composites with $6 \mathrm{wt} \%$ of BC and BCAc, and $10 \mathrm{wt} \%$ of VC and VCAc.

without substantial fiber breakage. In addition, the presence of $\mathrm{BC}$ aggregates provides strong evidence of the poor dispersion of the reinforcement within the PLA matrix, and therefore of the non-homogeneity of these composites. A similar behaviour was observed with the VC fibers (Fig. 4B).

On the other hand, the SEM images of the acetylated BC- and VC-based composites (Fig. 4A and Fig. 4B) provide evidence of the strong interfacial adhesion between both the fibers and PLA, as shown by the fibers' breakage and their homogeneous dispersion within the matrix, without aggregate formation. This behaviour is obviously the result of surface acetylation that has conferred a less polar character to the cellulose fiber surface. Moreover, it is clearly observed that the characteristic nanoand micro-fibril network of $\mathrm{BC}$ is maintained and entirely impregnated by the PLA matrix. These results clearly support the superior mechanical properties of the BC-based composites, compared with those of their VC counterparts, as suggested by the mechanical tests discussed below.

\section{Thermal properties}

The thermal stability and degradation profiles of the composite materials were assessed by thermogravimetry (Fig. 5, Table 4). The TGA tracing of the PLA matrix exhibits a typical single weight-loss step, with a maximum decomposition rate at $368^{\circ} \mathrm{C}$ (Fig. 5). The thermal decomposition process of all the PLA$\mathrm{BC}$ and PLA-VC composites also presented a single weight loss step profile, but their thermal stability depended on the cellulose substrate used and the reinforcement content, as well as on the acetylation of the reinforcing fibers.

The incorporation of $10 \%$ of unmodified VC fibers did not affect the thermal stability of the composites, whereas the presence of 20 and $30 \%$ of $\mathrm{VC}$ resulted in a decrease by about $10{ }^{\circ} \mathrm{C}$ of both the initial and maximum degradation

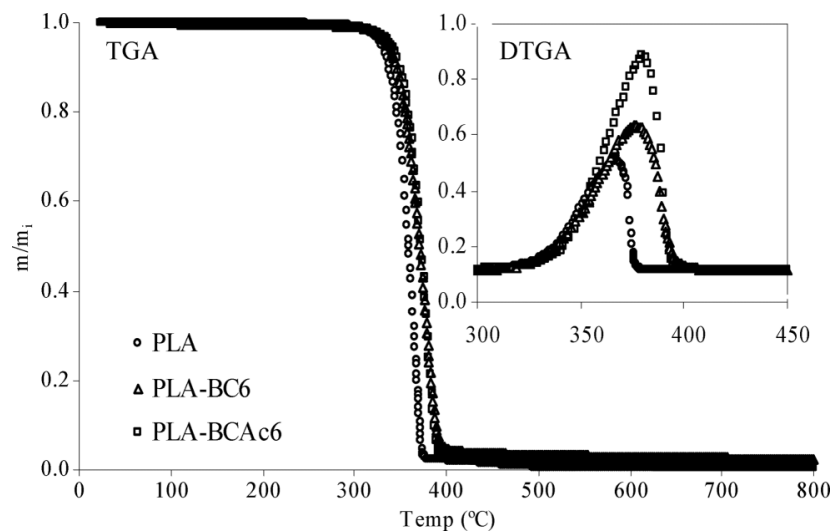

Fig. 5 Thermogravimetric curves for PLA and composites with $6 \mathrm{wt} \%$ of $\mathrm{BC}$ and acetylated $\mathrm{BC}$.

temperatures. Conversely, the stability of the composites with acetylated VC fibers was slightly higher than that of the neat PLA matrix, since a modest improvement (about $5{ }^{\circ} \mathrm{C}$ ) of the maximum degradation temperature was observed.

The incorporation of both unmodified and acetylated BC nanofibers in the PLA matrix (Fig. 5, Table 4) resulted in a considerable increase in the thermal stability of the corresponding composites, particularly those with acetylated BC fillers, as observed by the increment in both the initial and maximum degradation temperatures. For example, the incorporation of $6 \%$ of acetylated $\mathrm{BC}$ resulted in an increase of 15 and $14{ }^{\circ} \mathrm{C}$, respectively, in the initial and maximum degradation temperatures. Also worth mentioning is the fact that for PLA-BCAc nanocomposites, there was a clear increment in stability with increasing percentage of BCAc, almost certainly as a result of the good compatibility between PLA and BCAc. A similar behavior was previously reported for $\mathrm{BC}$ nanocomposites with 
Table 4 Melting temperature $\left(T_{\mathrm{m}}\right)$, melting enthalpy $\left(\Delta H_{\mathrm{m}}\right)$ and degree of crystallinity $\left(\chi_{\mathrm{c}}\right)$ of PLA-based BC and VC composites, as determined from DSC and TGA curves

\begin{tabular}{lllllll}
\hline & \multicolumn{2}{c}{$\mathrm{TGA}$} & \multicolumn{3}{c}{$\mathrm{DSC}$} \\
\cline { 2 - 3 } \cline { 6 - 7 } Sample & $T_{\mathrm{di}}$ & $T_{\mathrm{d} \max }$ & & $T_{\mathrm{m}} /{ }^{\circ} \mathrm{C}$ & $\Delta H_{\mathrm{m}} / \mathrm{J} \mathrm{g}^{-1}$ & $\chi_{\mathrm{c}}(\%)$ \\
\hline PLA & 330 & 368 & & 160 & 42.7 & 46 \\
& & & & & \\
PLA-BC1 & 339 & 375 & & 160 & 39.4 & 42 \\
PLA-BC4 & 335 & 377 & & 159 & 40.9 & 44 \\
PLA-BC6 & 336 & 377 & & 159 & 39.7 & 43 \\
PLA-BCAc1 & 332 & 374 & & 160 & 47.4 & 51 \\
PLA-BCAc4 & 338 & 382 & & 159 & 44.7 & 48 \\
PLA-BCAc6 & 345 & 382 & & 159 & 43.5 & 47 \\
& & & & & \\
PLA-VC10 & 330 & 368 & & 160 & 43.0 & 51 \\
PLA-VC20 & 319 & 356 & & 161 & 37.7 & 51 \\
PLA-VC30 & 319 & 359 & & 160 & 27.5 & 42 \\
PLA-VCAc10 & 336 & 376 & & 159 & 37.6 & 45 \\
PLA-VCAc20 & 328 & 373 & & 159 & 45.0 & 61 \\
PLA-VCAc30 & 317 & 373 & & 159 & 30.9 & 48 \\
\hline
\end{tabular}

thermoplastic $\operatorname{starch}^{28}$ and acrylic thermoplastic resins. ${ }^{29} \mathrm{~A}$ modest increment in thermal stability has also been recently observed in PLA composites reinforced with acetylated MFC. ${ }^{25}$ However, the effects observed were much less striking than those reported here, with an increment of only $3{ }^{\circ} \mathrm{C}$ in the initial degradation temperature, reached at substantially higher reinforcing contents, i.e. $17.3 \%$. Furthermore, the composites prepared with unmodified $\mathrm{MFC}^{25}$ were substantially less stable than the matrix.

The results reported here certainly reflect the excellent dispersion and good compatibility/adhesion between the acetylated BC nanofibers (and also the acetylated VC fibers) and the PLA matrix, as confirmed by the SEM imaging studies, as well as by the outstanding performance of the $\mathrm{BC}$ nanofillers associated with their natural nanofibrilar structure, high crystallinity and purity. ${ }^{37}$

The melting temperature $\left(\mathrm{T}_{\mathrm{m}}\right)$, enthalpy of fusion $\left(\Delta H_{\mathrm{m}}\right)$ and the degree of crystallinity $\left(\chi_{c}\right)$, determined from the DSC curves, of all composites are displayed in Table 4. The addition of unmodified and acetylated $\mathrm{VC}$ or $\mathrm{BC}$ fibers did not affected the melting temperature, as previously observed with other cellulose fiber-based PLA composites. ${ }^{5,24-25}$ As expected, the enthalpy of fusion $\left(\Delta H_{\mathrm{m}}\right)$ decreased with the fiber loading due to a corresponding decrease in the amount of matrix. In the case of the BC composites, this effect was not clearly observed because of the very low $\mathrm{BC}$ loads used.

Moreover, the degree of crystallinity of the PLA matrix was not significantly affected by the addition of $\mathrm{BC}$ or $\mathrm{VC}$ fibers; therefore, the improvement of the mechanical properties of the composites should be mainly due to the reinforcement effect of the cellulose fibers, rather than to the incrementing of the crystallinity. In fact, in some cases, this last parameter slightly decreased with the fibers' addition and an improvement in mechanical properties was still observed.

\section{Mechanical properties}

Fig. 6 and Fig. 7 show the curves of $\left(E^{\prime} / \mathrm{Pa}\right)$ (storage tensile modulus) and $\tan \delta$ (tan delta) of all the composites prepared
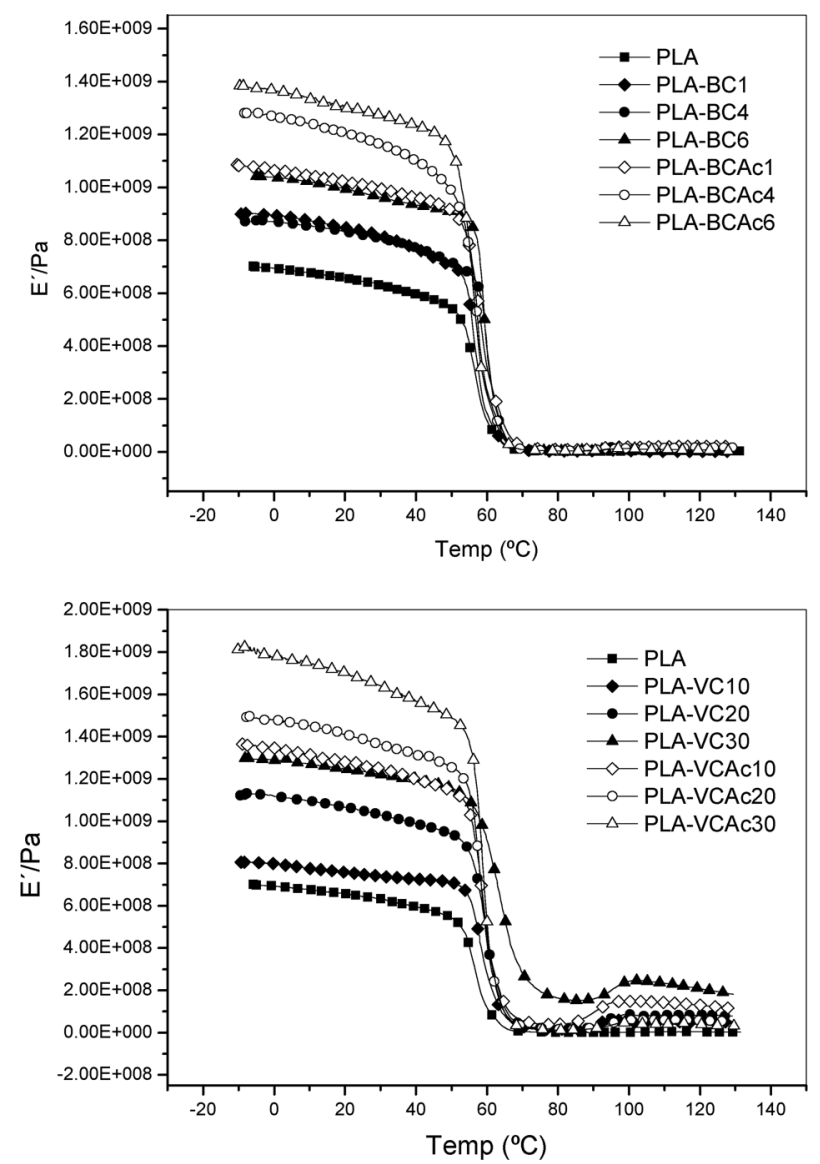

Fig. 6 Storage modulus $E^{\prime} v$ s. temperature (at $4 \mathrm{~Hz}$ ) of all the $\mathrm{BC}$ - and VC-based PLA composites.

in this study as a function of temperature. Specifically, the effect of the nature of the cellulose substrate (BC and VC), the surface acetylation and the filler load on the viscoelastic properties of the neat PLA were assessed.

The unfilled PLA showed a typical behaviour with three different regions. In the glassy state, the tensile storage modulus $E^{\prime}$ only slightly decreased with temperature, and then dropped considerably in the range $50-80^{\circ} \mathrm{C}$, with a maximum at around $67^{\circ} \mathrm{C}$. This relaxation phenomenon is associated with the glassrubber transition of the polymer.

All the composites showed higher storage moduli than that of neat PLA, but the increments observed differed from sample to sample. This effect was more pronounced for both $\mathrm{BC}$ and $\mathrm{VC}$ acetylated fillers, and increased with increasing fiber content. For example, the addition of $6 \%$ of $\mathrm{BC}$ and BCAc promoted an increment of about 40 and $100 \%$ in the elastic modulus $\left(\right.$ at $20^{\circ} \mathrm{C}$ ), respectively. Moreover, the increments promoted by the addition of $\mathrm{BC}$ nanofibers were much more attractive because of the very low $\mathrm{BC}$ loads used $(1,4$ and $6 \%$ vs. 10, 20 and $30 \%$, respectively, for $\mathrm{BC}$ and $\mathrm{VC}$ ). These results reflect, on the one hand, the excellent reinforcement effect of $\mathrm{BC}$ nanofibers compared to their VC counterparts, which is intimately associated with their three-dimensional nano- and microfibrilar network. On the other hand, the considerable improvement of the cellulose-PLA matrix interfacial adhesion, endorsed by the surface chemical acetylation of the cellulose substrates, must be considered an 

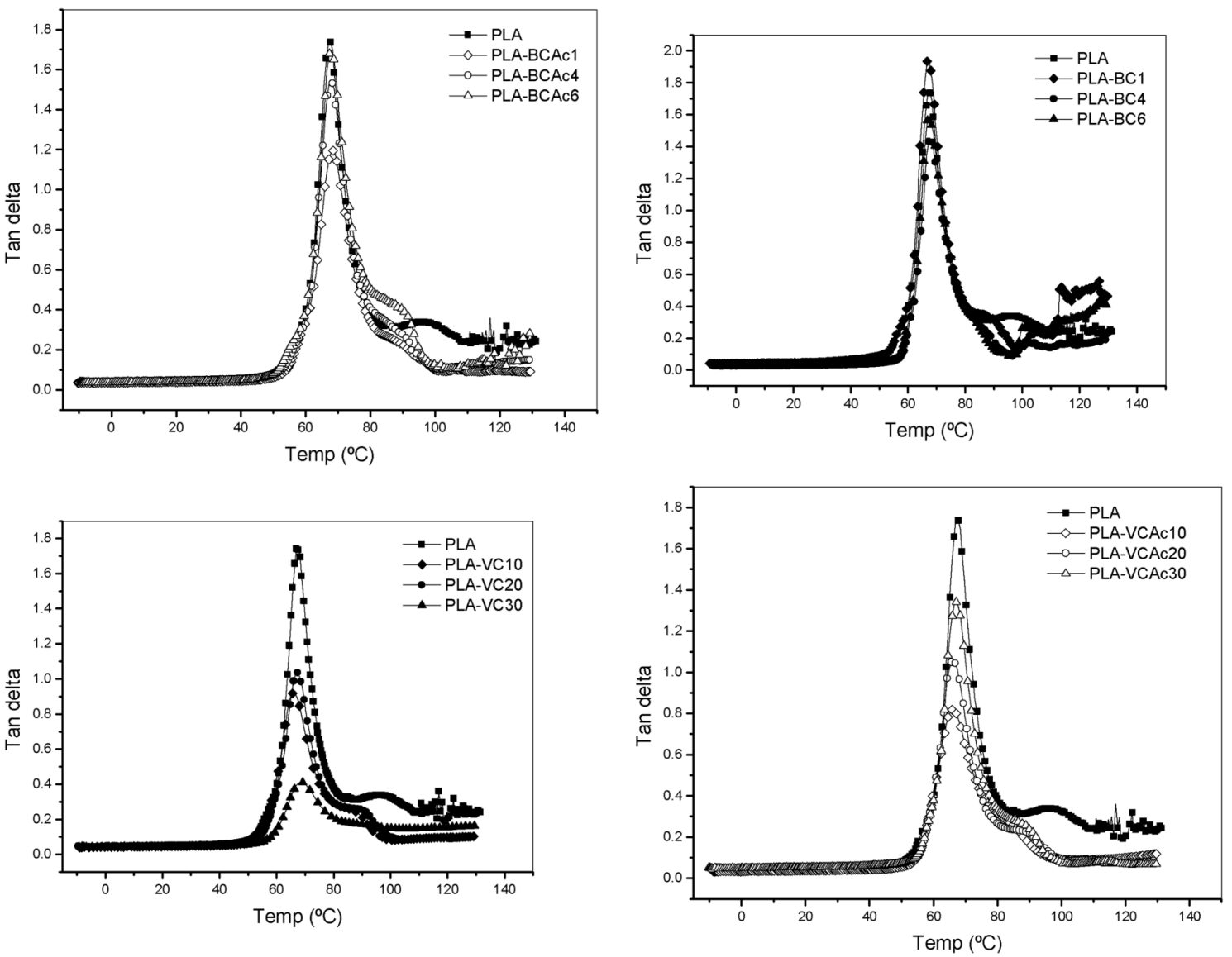

Fig. 7 Temperature dependence of $\tan \delta$ of all the BC- and VC-based PLA composites.

additional key element of the mechanical reinforcement. The increments in the elastic modulus (in the glassy state) observed for PLA nanocomposites with $\mathrm{BC}$ were considerably higher than those reported for similar composites with MFC. ${ }^{25}$ In fact, in that specific study, only at 10 and $17 \%$ MFC contents did the studied nanocomposites show a higher modulus than that of neat PLA, with the unmodified and acetylated MFC fillers promoting similar increments.

The evolution of the damping factor tangent of the loss angle (Tan $\delta$ ) as a function of temperature for the unfilled PLA and the corresponding BC- and VC-based composites displayed a maximum at around $67{ }^{\circ} \mathrm{C}$, associated with the glass transition of PLA (Fig. 7), as previously discussed for the variation of the storage modulus $E^{\prime}$ (Fig. 6). The $T_{\mathrm{g}}$ peak maximum of the PLA matrix was not hardly affected by the incorporation of $\mathrm{BC}$ and VC fibers, with only a $1-2{ }^{\circ} \mathrm{C}$ increase for the acetylated $\mathrm{BC}$ based composites. This increment was most probably due to the favourable interactions established between the acetylated $\mathrm{BC}$ and PLA in the composites. However, the very low BC loadings were not sufficient to produce a profound impact on the mobility of the matrix chains.

It was also observed (Fig. 7) that, in general, the magnitude of this relaxation process, which is related to the magnitude of the storage modulus drop, strongly decreases with increasing filler content. This behaviour is normally ascribed to the decrease in the matrices' relative mass, responsible for the damping properties, i.e. a decrease in the number of mobile units that participate in the relaxation phenomenon. However, the relative damping is not only related to the filler volume fraction and could indeed be influenced here by interfacial events between the two components of the composite.

Fig. 8 shows the tensile mechanical properties, including the Young modulus $(E)$, tensile strength and elongation at breakage, determined from the typical stress-strain curves. The Young moduli of all the $\mathrm{BC}$ and $\mathrm{VC}$ composites were higher than those of the unfilled PLA, and increased with filler content. In addition, the increments were much more pronounced for the acetylated $\mathrm{BC}$ and $\mathrm{VC}$ composites. These results are in excellent agreement with the DMA measurements.

The tensile strength also increased with increasing $\mathrm{BC}$ and $\mathrm{VC}$ load. Additionally, the presence of $\mathrm{BC}$ and $\mathrm{VC}$ reinforcements caused a considerable decrease in the elongation at breakage.

\section{Water uptake}

Water sensitivity is a crucial aspect of cellulose-based composites because the moisture picked up upon immersion in water or in high humidity environments is detrimental to their mechanical strength and dimensional stability.

Fig. 9 displays the water uptake progress for unmodified and acetylated, BC- and VC-based PLA composites as a function of 

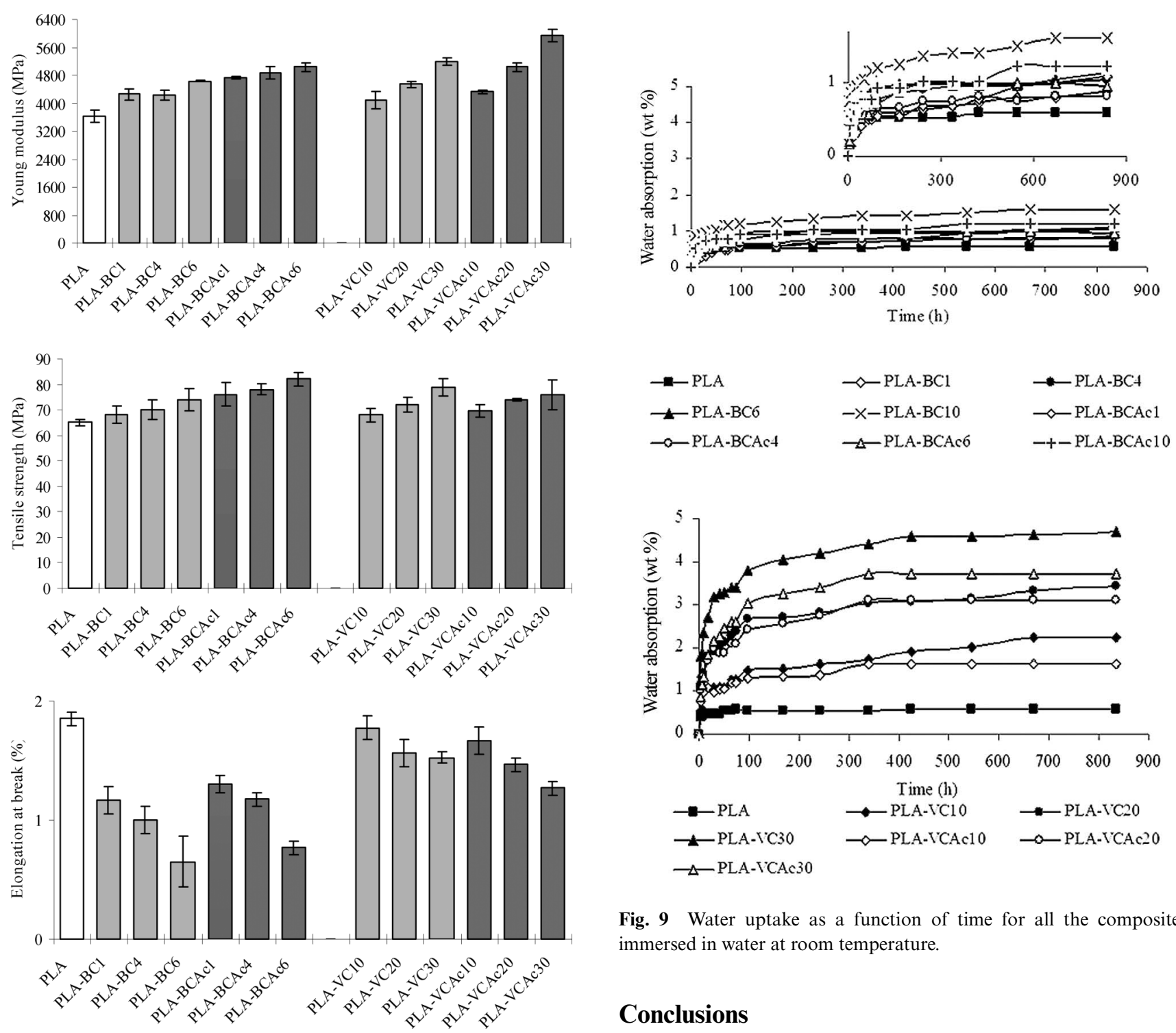

Fig. 9 Water uptake as a function of time for all the composites immersed in water at room temperature.

\section{Conclusions}

Fig. 8 The Young modulus (top), tensile strength (middle) and elongation at breakage (bottom) of all the BC- and VC-based PLA composites determined at room temperature.

time. All the composites absorbed water during the experiments, following similar patterns. After a relatively fast moisture uptake during the first day, the water sorption slowed down, leading gradually to a plateau. However, after 1 month in water, only the composites with acetylated cellulose fibers had reached such an equilibrium moisture level.

Since PLA only showed a small water uptake after 1 month (about $0.4 \%$ ) due to its hydrophobic nature, the water uptake of the composites was mainly due to the addition of $\mathrm{BC}$ or VC fibers and was commensurate with the reinforcement content. Therefore, the BC nanocomposites absorbed much lower amounts of water because of the very low loadings. Moreover, this parameter was higher for the unmodified BCand VC-based composites, reflecting the increase of the fibers' hydrophobicity after acetylation.

In the present work, novel biocomposites with improved properties were prepared from PLA and acetylated BC (and VC) through a simple and green approach. Surface acetylation of the cellulose substrates increased substantially their hydrophobicity and therefore their compatibility with the PLA matrix, as evidenced by SEM analyses. As a result, these composite materials showed an enhanced uniformity, filler dispersion, thermal and mechanical properties, as well as a lower water sensitivity, when compared with those of unmodified $\mathrm{BC}$ or VC fillers. Moreover, the composites with acetylated $\mathrm{BC}$ were considerably transparent and displayed globally better properties than their $\mathrm{VC}$ counterparts, considering that the $\mathrm{BC}$ contents used $(1,4$ and $6 \%$ ) were much lower that those of $\mathrm{VC}(10,20$ and $30 \%)$.

\section{Acknowledgements}

FCT (Fundação para a Ciência e Tecnologia) is acknowledged for L. C. T. (Research grant PTDC/QUI/68472/2006) and for E. T. (Postdoctoral research grant SFRH/BPD/63250/2009), and for L. C. T. financial support under the scope of the Convénio FCT-CAPES 2009. The authors thank the FCT 
for funding within the scope of the "National Program for Scientific Re-equipment" (Rede/1509/RME/2005 and REEQ/515/CTM/2005). The authors would also like to thank Prof. John Dorgan of the Colorado School of Mines for kindly providing the PLA sample and Prof. Aprígio Curvelo of the Instituto de Química de São Carlos for his experimental support with the mechanical experiments.

\section{References}

1 M. N. Belgacem, and A. Gandini, Monomers Polymers and Composites from Renewable Resources, Elsevier, Amsterdam 2008.

2 L. Avérous, in Monomers Polymers and Composites from Renewable Resources, ed. M. N. Belgacem and A. Gandini, Elsiver, Amsterdam 2008.

3 A. P. Mathew, K. Oksman and M. Sain, J. Appl. Polym. Sci., 2006, 101, 300-310.

4 K. Okubo, T. Fujii and E. T. Thostenson, Composites, Part A, 2009, 40, 469-475.

5 M. D. Sanchez-Garcia, E. Gimenez and J. M. Lagaron, Carbohydr. Polym., 2008, 71, 235-244.

6 M. Thunwall, A. Boldizar, M. Rigdahl, K. Banke, T. Lindstrom, H. Tufvesson and S. Hogman, J. Appl. Polym. Sci., 2008, 107, 918929.

7 R. A. Shanks, A. Hodzic and D. Ridderhof, J. Appl. Polym. Sci., 2006, 99, 2305-2313.

8 L. Petersson and K. Oksman, Compos. Sci. Technol., 2006, 66, $2187-$ 2196.

9 A. N. Nakagaito, A. Fujimura, T. Sakai, Y. Hama and H. Yano, Compos. Sci. Technol., 2009, 69, 1293-1297.

10 A. Iwatake, M. Nogi and H. Yano, Compos. Sci. Technol., 2008, 68, 2103-2106.

11 L. Suryanegara, A. N. Nakagaito and H. Yano, Compos. Sci. Technol., 2009, 69, 1187-1192.

12 K. Oksman, A. P. Mathew, D. Bondeson and I. Kvien, Compos. Sci. Technol., 2006, 66, 2776-2784.

13 L. Petersson, I. Kvien and K. Oksman, Compos. Sci. Technol., 2007, 67, 2535-2544.

14 D. Y. Liu, X. W. Yuan, D. Bhattacharyya and A. J. Easteal, eXPRESS Polym. Lett., 2010, 4, 26-31.

15 J. K. Pandey, C. S. Lee and S.-H. Ahn, J. Appl. Polym. Sci., 2010, 115, 2493-2501.

16 Y. Kim, R. Jung, H. S. Kim and H. J. Jin, Curr. Appl. Phys., 2009, 9, S69-S71.
17 F. Quero, M. Nogi, H. Yano, K. Abdulsalami, S. M. Holmes, B. H. Sakakini and S. J. Eichhorn, ACS Appl. Mater. Interfaces, 2009, 2 , 321-330.

18 B. L. Shah, S. E. Selke, M. B. Walters and P. A. Heiden, Polym. Compos., 2008, 29, 655-663.

19 M. Takatani, K. Ikeda, K. Sakamoto and T. Okamoto, J. Wood Sci., 2008, 54, 54-61.

20 M. S. Huda, L. T. Drzal, M. Misra and A. K. Mohanty, J. Appl. Polym. Sci., 2006, 102, 4856-4869.

21 L. Yu, S. Petinakis, K. Dean, A. Bilyk and D. Y. Wu, Macromol. Symp., 2007, 249-250, 535-539.

22 F. Chen, L. S. Liu, P. H. Cooke, K. B. Hicks and J. W. Zhang, Ind. Eng. Chem. Res., 2008, 47, 8667-8675.

23 B. Braun, J. R. Dorgan and D. M. Knauss, J. Polym. Environ., 2006, 14, 49-58.

24 K. Y. Lee, J. J. Blaker and A. Bismarck, Compos. Sci. Technol., 2009, 69, 2724-2733.

25 P. Tingaut, T. Zimmermann and F. Lopez-Suevos, Biomacromolecules, 2010, 11, 454-464.

26 C. S. R. Freire, A. J. D. Silvestre, C. P. Neto, M. N. Belgacem and A. Gandini, J. Appl. Polym. Sci., 2006, 100, 1093-1102.

27 C. S. R. Freire, A. J. D. Silvestre, C. P. Neto, A. Gandini, L. Martin and I. Mondragon, Compos. Sci. Technol., 2008, 68, 3358-3364.

28 I. M. G. Martins, S. P. Magina, L. Oliveira, C. S. R. Freire, A. J. D. Silvestre, C. P. Neto and A. Gandini, Compos. Sci. Technol., 2009, 69, 2163-2168.

29 E. Trovatti, L. Oliveira, C. S. R. Freire, A. J. D. Silvestre, C. Pascoal Neto, J. J. C. Cruz Pinto and A. Gandini, Compos. Sci. Technol., $2010,70,1148-1153$.

30 S. C. M. Fernandes, L. Oliveira, C. S. R. Freire, A. J. D. Silvestre, C. P. Neto, A. Gandini and J. Desbrieres, Green Chem., 2009, 11, 2023-2029.

31 C. P. Neto, A. J. D. Silvestre, D. Evtuguin, C. S. R. Freire, P. C. R. Pinto, A. S. Santiago, F. P. and B. Holmbom, Nord. Pulp Pap. Res. J., 2004, 19, 513-520.

32 G. Frisoni, M. Baiardo, M. Scandola, D. Lednická, M. C. Cnockaert, J. Mergaert and J. Swings, Biomacromolecules, 2001, 2, 476-482.

33 C. Vaca-Garcia, M. E. Borredon and A. Gaset, Cellulose, 2001, 8, 225-231.

34 D. K. Owens and R. C. Wendt, J. Appl. Polym. Sci., 1969, 13, 17411747.

35 L. J. Bellamy, The Infrared Spectra of Complex Molecules, Chapman and Hall, London, 1975.

36 G. Meshitsuka and A. Isogai, in Chemical Modification of Lignocellulosic Materials, ed. D. N.-S. Hon, CRC Press, 1995, pp. 11-34.

37 D. Klemm, B. Heublein, H.-P. Fink and A. Bohn, Angew. Chem., Int. Ed., 2005, 44, 3358-3393. 